\title{
MEDICAL STUDENTS' KNOWLEDGE OF THE CHARACTERISTIC FEATURES AND PREVENTION OF TUBERCULOSIS
}

\author{
G. Tsankova, B. Yustiniyanova \\ Medical College \\ Prof. Paraskev Stoyanov Medical University of Varna
}

\section{SUMMARY}

Medical students' knowledge of the main characteristic features of tuberculosis and the prevention of the disease was studied by means of an anonymous inquiry examination of 84 students of the Medical College of Varna during the 2009/2010 academic year. They presented with good knowledge of the main characteristics of tuberculosis such as predisposing factors, risk groups, source and mechanism of transmission of the infection. They were better grounded in the common preventive measures for avoiding the tuberculosis infection rather than in those towards the contact persons. Most respondents indicated the role of Mantoux test (61\%) and microbiological examination of sputum.

Key words: tuberculosis, inquiry, bachelors, education, risk factors, prevention

\section{INTRODUCTION}

According to WHO data, the patients with tuberculosis amount to more than 15 millions worldwide. In 2007, the prevalence rate of tuberculosis in Europe was 54 per 100000 inhabitants. In Bulgaria, the prevalence rate of tuberculosis remains at a middle level being 37 per 100000 in the regions with the highest rates. In 2009, a total of 3164 cases of tuberculosis were registered of which 2832 represented new cases of the disease [1]. From the onset of 2009 till the end of the first trimester of 2010, 151 newlydiagnosed cases were registered in the city of Varna. With the purpose of reducing the morbidity rate of tuberculosis, a Programme for tuberculosis control improvement in Bulgaria financially supported by the Global fund for struggle against AIDS, tuberculosis, and malaria is being executed from 2007 till 2012 [1].

After appreciation of the health and social significance of this problem we set us the TASK of studying medical students' knowledge of the main characteristic features of the tuberculosis process and the prevention of the disease.

\section{MATERIALS AND METHODS}

An anonymous inquiry examination covered 84 students of different specialties and courses of study at a mean age of $21 \pm 2,5$ years. Of them, $17 \%$ were males and $83 \%$ were females. They were enrolled in the Medical College of Varna as professional bachelors during the 2009/2010 academic year. The questionnaire contained 32 questions divided into 4 sections. SPSS ver. 16,0 software package was used for statistical data processing.

\section{RESULTS AND DISCUSSION}

The main predisposing factors for the dissemination of tuberculosis in Eastern Europe are the following: low socio-economic status of the population, unemployment, inadequate nutrition, high density of population, close contact with tuberculosis patients, etc. [3,7]. The risk of pulmonary tuberculosis is higher among active smokers and consumers of more than $40 \mathrm{~mL}$ of alcohol daily [5].

According to the results from this investigation, the most common predisposing factors for tuberculosis indicated by the interviewed persons are the decreased protective forces of the organism (in $95 \%$ of the responses), poor hygienic living conditions (in $89 \%$ ), unhealthy nutrition (in 57\%), tobacco smoking (in 55\%), experienced acute infectious diseases such as influenza, morbilli, and epidemic parotitis (in 54\%), and alcohol abuse (in 23\%). Data analysis demonstrates that $11 \%$ of the students are very well acquainted with the predisposing factors for tuberculosis as they have indicated 6-7 correct answers while $33 \%$ of the respondents are sufficiently familiar with the problem as they have indicated 4-5 correct answers. These factors remain unknown for $10 \%$ of the students mainly from the first academic year as less than two correct answers have been indicated only (Fig. 1). It stresses that $45 \%$ of the students who have marked the tobacco smoking as a risk factor are, in fact, active smokers. The comparison according to the different specialties demonstrates that the relative share of the active smokers is highest (of 49\%) among the medical laboratory assistants of whom $91 \%$ are female adolescents. 


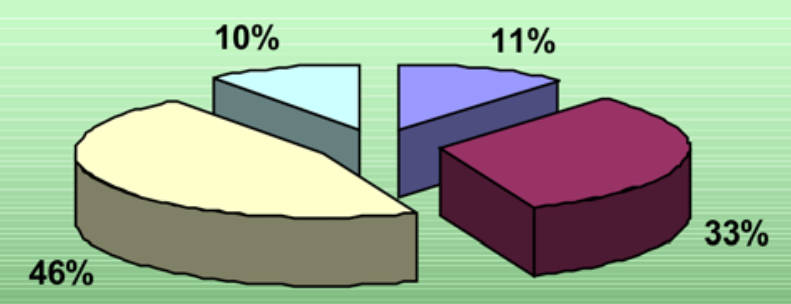

$\square$ very well acquainted $\square$ well acquainted $\square$ partially acquainted $\square$ not acquainted at all

Fig. 1. Level of students' knowledge of the predisposing factors for tuberculosis

Concerning the question "What are the risk groups for tuberculosis?", $75 \%$ of the students indicate the patients with chronic bronchitis, pneumoconioses, and pneumofibrosis; $58 \%$ outline HIV-infected patients, while $19 \%$ consider the patients undergoing long-lasting cortisone medication predisposed to tuberculosis, too. The air-drop route of transmission of the infection is most known. It has been marked by $82 \%$ of the respondents. Next comes the transplacental (mother-to-foetus) mechanism (in $28 \%$ of the responses) followed by the alimentary one (in $18 \%$ of the cases).

Our results demonstrate that $100 \%$ of the respondents have correctly noted that the patients with tuberculosis and carriers of the disease represent the source of infection. The relative share of the students who are aware of the fact that cows as well as birds and pigs with tuberculosis can serve as source of infection, too (in $9 \%$ and $6 \%$ of the cases, respectively). Only one student reports that an own family member has suffered from tuberculosis. According to the distribution of specialties, public health inspectors and assistant pharmaceutists present with better knowledge than the rest students $(\mathrm{p}<0,01)$ (Fig. 2).

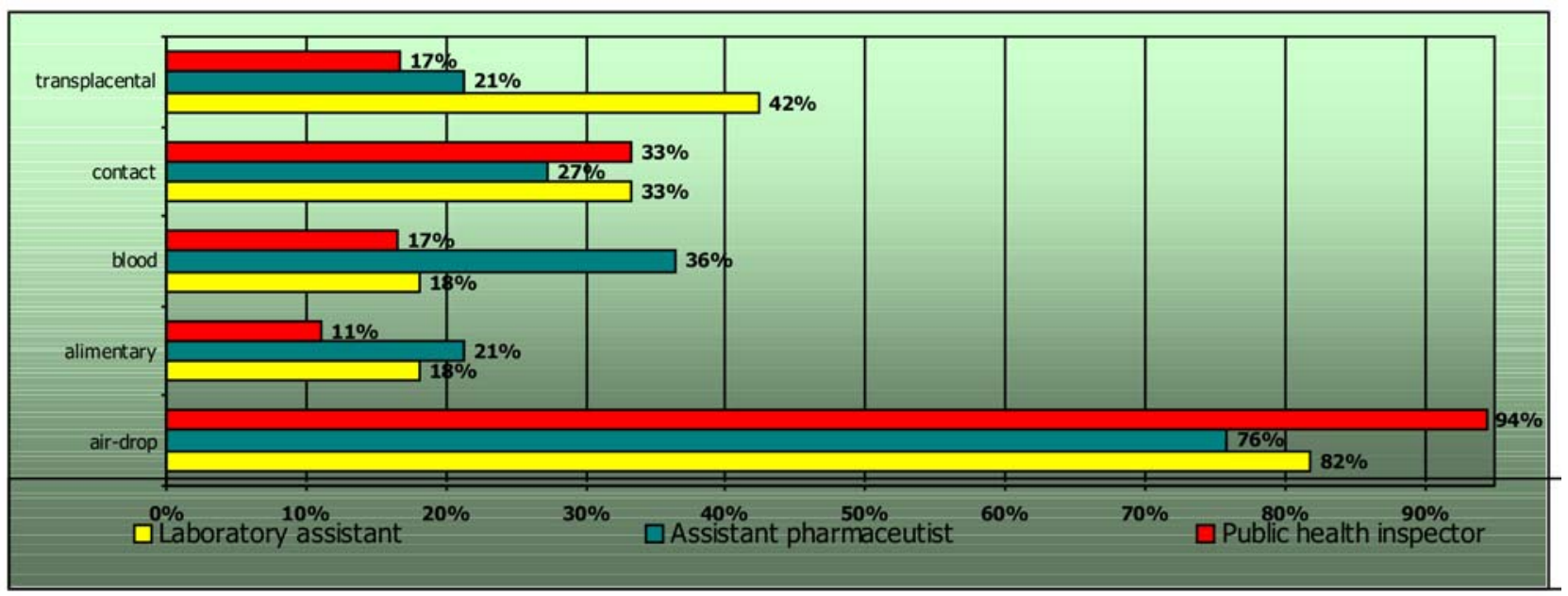

Fig. 2. Relative share (in \%) of the correct responses concerning the mechanism of transmission of tuberculosis

Knowledge of the typical symptoms of the disease is of importance for early diagnosis of pulmonary tuberculosis and timely initialization of a full-value, longlasting and continuous chemotherapy which warrants the effective treatment of the patients [2].

According to students' opinion, the pathognomonic symptoms of the pulmonary tuberculosis are the following: cough of duration more than 2 weeks has been indicated by a total of $81 \%$ of the respondents of the three specialties, bloody expectorations - by $65 \%$ of the cases, and chest pains - by $54 \%$ of the cases. Knowledge of assistant pharmaceutists and laboratory assistants is reliably better expressed $(p<0,05)$. On the average of $33 \%$ of the students from the three specialties falsely indicate that jaundice is a cardinal symptom of tuberculosis which represents a gap in their education (Fig. 3).

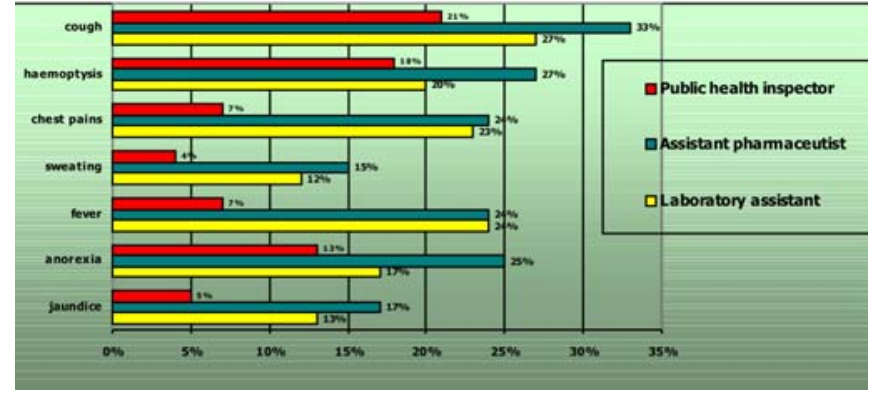

Fig. 3. Medical students' knowledge of the clinical symptoms of localized pulmonary tuberculosis

The results from the inquiry show that the students are familiar with the preventive measures against tuberculosis. Maintenance of good individual and public 
hygienic standards has been indicated by $94 \%$ of the public health inspectors as future state employees implementing the state health control in the field of hygiene and epidemiology. This preventive measure has been outlined by a total of $88 \%$ of all the respondents. To the other prophylactic factors indicated by the students belong avoiding the contact with tuberculosis patients $(83 \%)$, healthy nutrition $(82 \%)$, and thermal processing of the foodstuffs ( $51 \%$ of the cases). Unboiled milk consumption is the most important predisposing factor for tuberculosis [3]. Only $36 \%$ of the respondents are aware of the fact that pasteurized milk has to be additionally boiled not less than $5 \mathrm{~min}$. long. Physical endurance and sports are considered preventive measures by $65 \%$ of the students. It is an alarming fact that $71 \%$ of the students from the different specialties do not engage regularly in sports, i. e. at least once weekly. This is more manifested among the assistant pharmaceutists and public health inspectors. The students from the specialty of laboratory assistant who regularly go in for sports present with the highest relative share in this respect (13\% of the cases) (Fig. 4).

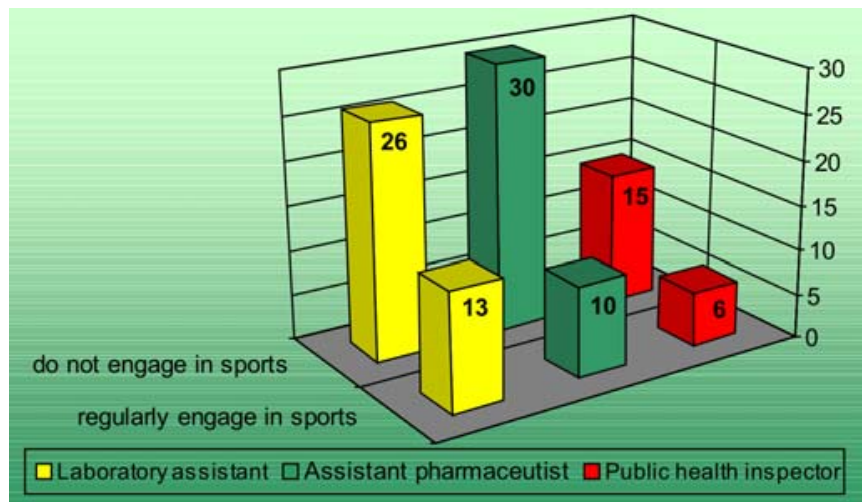

Fig. 4. Relative share (in \%) of the students regularly engaged in sports
Primary prevention includes immunoprophylaxis with BCG vaccine and chemoprophylaxis as well [6]. It represents a criterion for reduction of tuberculosis morbidity rate and that is why the students should be well grounded in it. Most respondents are familiar with the specific prevention of tuberculosis as $79 \%$ of them report that they have undergone a BCG vaccination. Besides, $83 \%$ of them have already been examined by Mantoux test which has been read by their general practitioner in $71 \%$ of the cases. However, this test has not been performed in 3\% of the respondents.

Concerning the question "Which preventive measures should be taken towards the contact persons with tuberculosis? (i. e. who live and work in one and the same room with tuberculosis patients)", $61 \%$ of the students indicate Mantoux test, $58 \%$ outline the microbiological examination of the sputum and only $9 \%$ emphasize the chemoprevention. The laboratory assistants are better grounded in these measures. Of them, $70 \%$ indicate Mantoux test and $73 \%$ indicate the microbiological examination of the sputum.

\section{CONCLUSION}

The inquired students present with relatively good medical knowledge of the main characteristics of tuberculosis such as predisposing factors, risk groups, source and mechanism of transmission of the infection as well. There are better grounded in the specific prevention of tuberculosis rather than in the preventive measures which should be taken towards the contact persons. Taking into consideration the rising tuberculosis incidence rate it seems necessary to focus students' attention on the specific symptoms of pulmonary tuberculosis and the measures towards the contact individuals.

\section{REFERENCES:}

1. Златев, Ас. Туберкулозата вчера и днес. - Наука пулмология, 2009, № 2, с. 43.

2. Златев, Ас., Ат. Златев. Лечение на белодробната туберкулоза.- Наука пулмология, 2009, № 2, 48-52.

3. Coker, R., M. McKee, R. Atun, B. Dimitrova, E. Dodonova, S. Kuznetsov, F. Drobneiwski. Risk factors for pulmonary tuberculosis in Russia: a case-control study.-
British Medical Journal, 322, 2006, No 7533, 85-87.

4. Lin, H-H., M. Ezzati, M. Murray. Tobacco smoke, indoor air pollution and tuberculosis: a systematic review and metaanalysis.- PloS Medicine, 4, 2007, No 1, e20.

5. Lцnnroth, K., B. G Williams, S. Stadlin, E. Jaramillo, C. Dye. Alcohol use as a risk factor for tuberculosis - a systematic review.- BMC Public Health, 8,
2008, 289.

6. Okoh, A. Prevention and control of tuberculosis.- Benin Journal of Postgraduate Medicine, 11, 2009, Supplementary Issue, 97-99.

7. Tekkel, M., M. Rahu, H-M. Loit, A. Baburin. Risk factors for pulmonary tuberculosis in Estonia.- International Journal of Tuberculosis and Lung Diseases, 6, 2002, No 10, 887-894.

\author{
Address for correspondence: \\ Gabriela Tsankova \\ Medical College of Varna; Prof. Paraskev Stoyanov Medical University of Varna \\ 84 Tsar Osvoboditel Street, BG-9002 Varna, Bulgaria \\ E-mail: gabriela_sc@abv.bg
}

